\title{
DIÁLOGOS TRANSATLÂNTICOS: AFRICANIDADE, NEGRITUDE E CONSTRUÇÃO DA IDENTIDADE
}

\author{
Deolinda Adão \\ (University of California, Berkeley - EUA)
}

\section{RESUMO}

O trabalho aborda os diálogos, tanto ao nível estético quanto ideológico, entre movimentos Pan-Africanistas como o da Renascença de Harlem, o movimento de Negritude Francês e a produção artística, particularmente a literária, dos estudantes da Casa do Império em geral e de Francisco José Tenreiro em particular.

PALAVRAS-CHAVE: Africanidade; Negritude; Pan-Africanismo; Construção de Identidade.

\begin{abstract}
The article explores the aesthetic and ideological dialogs between Pan-African movements, such as the Harlem Renaissance, the French Negritude movement, and the artistic, particularly the literary production of the student of the Casa do Império in general and that of Francisco José Tenreiro in particular.
\end{abstract}

KEYWORDS: Africanism; Negritude; Pan-Africanism; Identity construction. 
O objectivo principal deste trabalho é estabelecer uma ligação entre a produção literária dos escritores e poetas Africanos, particularmente a dos participantes do Boletim dos Estudantes do Império, Mensagem, e aquela desenvolvida pelos integrantes dos movimentos Pan-africanos noutros países, nomeadamente Estados Unidos e Cuba. Neste trabalho limitar-nos-emos a considerar os autores que participaram no movimento conhecido como Renascença de Harlem nos Estados Unidos e à geração de Nicolás Guillén em Cuba de forma a identificar pontos de contacto ou mesmo de intertextualidade entre estes autores e os representados em Mensagem. Esta abordagem, apesar de pouco explorada ${ }^{1}$, não é inédita, pois embora na introdução ao livro Negritude Africana de Língua Portuguesa Pires Laranjeira afirme que a origem da negritude lusófona é a négritude francófona ${ }^{2}$, vários dos ensaios incluídos nessa colectânea, nomeadamente os de Mário Pinto de Andrade e de Francisco José Tenreiro, desenvolvem a relação entre a negritude lusófona e o projecto Pan-africanista dos poetas do Renascença de Harlem e de outros movimentos de negritude latino-americanos, particularmente os desenvolvidos em Cuba.

De forma geral considera-se que o movimento político-cultural conhecido como Renascença de Harlem tem início quando em Fevereiro de 1919 o Regimento 369 das forças armadas americanas ${ }^{3}$ desfila em Nova York desde o princípio da Quinta Avenida até Harlem, e que se alarga até fins da década de quarenta ${ }^{4}$. Segundo George Hutchinson o movimento hoje conhecido como Renascença de Harlem foi na sua era designado Negro Renaissance e, mais do que um movimento cultural ou literário, foi uma sobreposição de círculos sociais e intelectuais, desenvolvimentos paralelos, grupos transversais e visões rivais unidos pelo desejo de reivindicação racial e auto-reconhecimento perante a supremacia Anglo-Americana ${ }^{5}$. Assim, os objectivos dos participantes no Renascença de Harlem estão em perfeita sintonia com os que já vinham a ser postulados nos Congressos Pan-Africanos que tinham sido organizados, na maioria dos casos por W. E. B DuBois, desde $1900^{6}$. Aliás, muitos dos congressistas, incluindo DuBois, também participaram activamente na Renascença de Harlem tanto na sua vertente política como na cultural. Portanto, cronologicamente, a Renascença de Harlem precede o movimento de Negrismo em Cuba ${ }^{7}$, que por sua vez é praticamente paralelo ao movimento de negritude francês que se considera ter iniciado em 1927 quando da publicação de La Revue Indigène por Jacques Roumain, e solidificado pela publicação em 1930 do texto frequentemente identificado como "Manifesto da Negritude" ou seja, o livro de poemas Pigments de Léon-Gontran Damas. Assim, o movimento de Negritude em língua portuguesa no qual participaram, entre outros, Mário Pinto de Andrade, Agostinho Neto, Francisco José Tenreiro, Alda Espírito Santo e José Craveirinha e que segundo Pires Laranjeira está circunscrita à produção literária, especialmente poética, destes autores entre 1949 e 1959. No entanto, a afirmação de Laranjeira no Prefácio a Negritude Africana de Lingua Portuguesa. Textos de Apoio (1947-1963), que vincula a génese deste movimento em Portugal com o que se desenvolveu em França - "a Negritude francófona (dos anos 30) foi assimilada, dando origem a uma Negritude lusófona" (LARANJEIRA, 2000, VII) - não desenvolve a noção que em realidade ambas estão inseridas no movimento político e cultural de Negritude Pan-Africana que se alargou de uma forma ou outra durante quase todo o século $\mathrm{XX}^{8}$, e como tal a produção literária dos poetas e intelectuais da Mensagem estava inevitavelmente também sob a influência dos participantes na Renascença de Harlem. 
No texto A Literatura Negra e os seus Problemas publicado em Mensagem, (ano III, n. 2 Jan.-Julho de 1951) e reproduzido em Negritude Africana de Língua_Portuguesa. Textos de Apoio (1947-1963), Mario Pinto de Andrade explicitamente estabelece a ligação entre toda a produção artística vinculada com África - "urge iniciar uma obra de interpretação de todas as nossas manifestações artísticas, espalhadas por todas as Áfricas do mundo" (ANDRADE, 1951, p. 3) -, define essa produção artística como uma produção transcontinental - "Quanto à outra literatura, a segunda, [a escrita] todos sabemos que não é só da África mas também das Américas" (ANDRADE, 1951, p. 3) -, e nomeia os participantes emblemáticos desse movimento pan-africano:

Só do desconhecimento (ou talvez o esquecimento) da existência dum Langston Hughes, dum Nicolás Guillén, Sédar Senghor ou Aimé Cesaire, pôde levar o Dr. Tomé das Neves' a afirmar que 'o poeta negro', afora uma ou outra excepção, não descreve o que sente, o que lhe vai no íntimo coo negro. Não revela a sua sensibilidade artística, descrevendo a alma negra, o sentimento negro. (Andrade, 4)

Na segunda parte de A Literatura Negra e os seus Problemas publicada em Mensagem (Ano III, n. 13, Janeiro de 1953), Pinto de Andrade continua a desenvolver a linha de pensamento iniciada na primeira parte do texto e efectua o percurso da literatura negra - não a oral, que segundo o autor se desenvolve primordialmente no continente africano, mas a escrita, a que está marcada por "assimilação total ou parcial da cultura do europeu e, por consequência, o conteúdo da obra e o problema da língua" (ANDRADE, 1953, p. 14) - e declara que "Na América do Norte e Central, encontrámos os maiores poetas da literatura negra." (ANDRADE, 1953, p. 14) Na América do Norte, após fazer referência aos "Espirituais" introduzidos nos Estados Unidos pelos escravos - e que para Andrade "marcam a primeira forma de expressão artística na literatura negra da América do Norte" (ANDRADE, 1953, p. 14) -, acompanha o percurso histórico tanto do Africano nos Estados Unidos, como da forma como a sua produção literária segue cada momento desse percurso, até ao momento de chegada ao que o autor identifica como "o realismo social de Countee Cullen, Claude Mckay, Langston Hughes e outros” (ANDRADE, 1953, p. 16), momento esse que para Andrade é "a hora de afirmação, de presença e de novos cantos." (ANDRADE, 1953, p. 16) No que se refere à América Latina, o autor cita José António Portuondo, que identifica Nicolás Guillén como a figura mais eminente do "movimiento negrista" que surge em 1930. Se bem que Portuondo considera que a grande influência desta poesia são os sons e os ritmos da arte negra popular, para Andrade, no caso de Guillén,

algo mais profundamente humano vai preencher o conteúdo da sua obra poética: a denuncia das injustiças sociais e em particular a presença do Homem Negro no mundo de todos os homens. E é neste aspecto que Nicolás Guillén é essencialmente um poeta negro: porque da sua poesia chega até nós a inquietação do Homem Negro, a sua negritude. (ANDRADE, 1953, p. 17) ${ }^{10}$

A temática desenvolvida por Pinto de Andrade nas duas partes do texto A Literatura Negra e os seus Problemas vai ser revisitada e ampliada em Poesia negra de expressão portuguesa na qual Andrade colabora 
com Francisco José Tenreiro. Neste texto, dedicado a Nicolás Guillén, que segundo os autores é "a voz mais alta da negritude de expressão hispano-americana” (LARANJEIRA, 2000, p. 19), os autores dissertam sobre o percurso da poesia negra e sobre as dificuldades inerentes à compilação de um Caderno de Poesia Negra. Neste texto Andrade e Tenreiro abordam o movimento de negritude da seguinte forma:

abre-se um novo caminho de reconquista dos valores perdidos. O negro-africano ocidentalizado, 'consumidor de civilização branca', exprime uma atitude, num movimento formalmente cultural - a negritude. Agora é o novo negro que surge entre duas guerras, consciente dos problemas da sua particular alienação, a alienação colonial e reivindica o seu lugar nos quadros da vida económica, social e política. (LARANJEIRA, 2000, p. 14)

Mais uma vez, as expressões de negritude da América do Norte e de Cuba são incluídas na análise dos autores como parte integrante de um movimento pan-africano:

Na América do Norte (...) o negro criou uma poesia das mais directas e revoltadas de toda a poesia universal, reflexo da luta violente que teve logo de travar com as condições opressivas do meio. (...) de J. Hammon a Countee Cullen e Langston Hughes, a poesia negra norte-americana é cada vez mais gritante; vem das fundas reminiscências africanas ao ritmo de velhos tambores, penetra fundo nas condições americanas, protesta e exige oportunidades na vida social.

Em Cuba (...) só em 1930, Nicolás Guillén e outros, para além de recriação das mais puras formas líricas do canto Yoruba, iniciaram de facto um movimento poético de sentido social e descobriram a sua "negrituge". (LARANJEIRA, 2000, p. 18)

Mário Pinto de Andrade continuaria a desenvolver o tema de uma negritude pan-africana em textos subsequentes como Poesia negro- africana de expressão portuguesa publicado em 1954 na Província de S. Pedro, no 19 , no Post scriptum a Cultura negro-africana e assimilação incluído na Antologia da Poesia Negra de Expressão Portuguesa de Pierre Jean Oswald ${ }^{11}$.

Também Francisco José Tenreiro - cuja obra poética, segundo Andrade, especialmente em Ilha de Nome Santo, publicado em 1942, ao proceder à "exaltação do homem negro de todo o mundo" (LARANJEIRA, 2000 , p. 16) se insere no movimento de negritude transcontinental e pan-africana e como tal entra em diálogo directo com Hughes e Guillén - voltaria a desenvolver o tema em Processo poesia ${ }^{12}$, neste caso dentro de um contexto da "poesia do Ultramar" e afirma que "foram esses poetas [os que participaram na negritude] que pela primeira vez, nos ritmos livres dos poemas equacionaram, aos que têm sensibilidade, as tensões sociais que estão na génese da problemática actual do mundo ultramarino." (LARANJEIRA, 2000, p. 67) A contribuição dos poetas da Renascença de Harlem e da Cubanidad volta a ser largamente desenvolvida por Tenreiro no texto Acerca da literatura negra (publicado no Comércio do Porto [Cultura e Arte], em Fevereiro de $1961^{13}$ ), no qual, e dentro de uma abordagem ao que o autor 
denomina como "grupo de literaturas crioulas" (LARANJEIRA, 2000, p. 74), Tenreiro afirma que Caboverdianidade surge por influência do termo Cubanidade "A palavra Cubanidade sugeriu a 'invenção' de uma outra: $\mathrm{Ca}$ boverdianidade." (LARANJEIRA, 2000, p. 74) Esta linha de pensamento seria ampliada no texto A poesia do negro "José Maria" publicado em primeira instância no Mundo Literário, (nº 16 [11-1-1947]) e posteriormente em Negritude Africana de Língua Portuguesa. Textos de Apoio (1947-1963) onde, para além de afirmar a relação entre os diversos movimentos de negritude, Tenreiro analisa de forma detalhada alguns poemas de Guillén concluindo que tanto este como os poetas da Renascença de Harlem desenvolveram e revelaram através da sua poesia a sua respectiva "consciência cultural." (LARANJEIRA, 2000, p. 84) Para além de Andrade e Tenreiro diversos outros ensaístas desenvolvem a relação entre a negritude americana, tanto a dos Estados Unidos como a Cubana, e a poesia Africana em língua portuguesa, como por exemplo Orlando de Albuquerque que no texto Introdução à poesia negra ${ }^{14}$ declara que todas as correntes de poesia negra evidenciam "uma ansiedade em caminhar de cabeça erguida e de mãos dadas." (LARANJEIRA, 2000, p. 108).

Existem inúmeros exemplos de intertextualidade directa entre autores africanos em língua portuguesa e os autores da Renascença de Harlem em alguns casos de forma explícita, através de dedicatória ou do título do poema, como no caso de Na morte de Langston Hughes, de Jofre Rocha (FERREIRA, 1986, p. 119), ou ainda no corpo do poema em si, como no caso de Deixa passar o meu povo, de Noémia de Sousa: "Mas vozes da América remexem-me a alma e os nervos./ E Robeson e Marian cantam para mim/ spirituals negros de Harlem./ 'Let my people go'/ - oh deixa passar o meu povo" (FERREIRA, 1986, p. 355). No entanto, dentro da poesia em língua portuguesa, um dos poetas onde encontramos fortes indícios de influência dos poetas da Renascença de Harlem e dos Cubanos da Cubanidad é sem dúvida Francisco José Tenreiro que frequentemente dialoga com a temática desses movimentos de negritude, segundo Martinho ${ }^{15}$ particularmente em Ilha de Nome Santo. Apesar de fazer parte de uma fase posterior de Tenreiro, no poema "Negro de todo o mundo" que está integrado em Coração em África, para além de fazer uma referência directa a Harlem, Tenreiro entra em diálogo com os poetas do Renascença de Harlem através da temática da dispersão da diáspora africana por todo o mundo, e da noção de um movimento de negritude transcontinental e pan-africano:

O som do gong

ficou gritando no ar

que o negro tinha perdido.

Harlem! Harlem!

América!

Nas ruas de Harlem

os negros trocam a vida por navalhas!

América! 
Nas ruas de Harlem

o sangue de negros e de brancos está formando xadrez.

Harlem!

$$
\begin{aligned}
& \text { Bairro Negro! } \\
& \text { Ring da vida! }
\end{aligned}
$$

Os poetas de Cabo Verde

estão cantando...

Cantando os homens

perdidos na pesca da baleia.

Cantando os homens

perdidos em aventuras da vida

espalhados por todo o mundo!

Em Lisboa?

$\mathrm{Na}$ América?

No Rio?

Sabe-se lá!...

- Escuta

É a Morna...

Voz nostálgica do cabo-verdiano chamando por seus irmãos!

Nos terrenos de fumo

os negros estão cantando.

Nos arranha-céus de New-York

os brancos macaqueando!

Nos terrenos da Virgínia

os negros estão dançando.

No show-boat do Mississipi

os brancos macaqueando!

Ah!

Nos estados do sul

Os negros estão cantando!

A tua voz escurinha

está cantando

nos palcos de Paris.

Folies-Bergères.

18 GBPYL - Revista do Núcleo de Estudos de Literatura Portuguesa e Africana da UFF, Vol. 4, n 7, novembro de 2011 
Os brancos estão pagando

o teu corpo

a litros de champagne.

Folies-Bergères!

Londres-Paris-Madrid

na mala de viagens...

Só as canções longas

que estão soluçando

dizem da nossa tristeza e melancolia!

Se fosses branco

terias a pele queimada

das caldeiras dos navios

que te levam à aventura!

Se fosses branco

terias os pulmões cheios

de carvão descarregado

no cais de Liverpool!

Se fosses branco

quando jogas a vida

por um copo de whisky

terias o teu retrato no jornal!

Negro!

Na cidade da Baía

Os negros

estão sacudindo os músculos.

Ui!

Na cidade da Baía

os negros

estão fazendo macumba.

O r a x i lá !

Oraxilá!

Cidade branca da Baía.

Trezentas e tantas igrejas!

Baía...

Negra. Bem negra!

Cidade de Pai de Santo.

O r a x i l á!

Oraxilá! 
Efectivamente, este tema acaba por ser um dos recorrentes em vários poetas Africanos, incluindo Agostinho Neto, que claramente o desenvolve no poema Aspiração: "Ainda o meu canto dolente / e a minha tristeza / no Congo, na Geórgia, no Amazonas" (FERREIRA, 1986, p. 28).

Em conclusão, embora a negritude africana de língua portuguesa esteja fortemente influenciada pela negritude francesa, o facto que tanto uma como outra estão directamente vinculadas com a Renascença de Harlem não pode ser ignorado, pois ao fazê-lo arriscamos menosprezar o valor da poesia africana em língua portuguesa dentro de um contexto internacional de literatura africana. Possivelmente o facto da produção literária dos poetas africanos que escreviam em língua portuguesa ter sido desenvolvida de forma semi-clandestina e dentro de um enquadramento político ditatorial e colonial contribuiu para um relativo estrangulamento na forma como as mesmas têm sido lidas e interpretadas. Em suma, o grande tema de todos os participantes dos diversos movimentos de negritude é a recuperação da dignidade colectiva perdida e a construção de uma voz representativa de realidade do homem negro, e como tão eloquentemente escreveu Mário Pinto de Andrade no texto Poesia negra de expressão portuguesa, esta era uma literatura que se destinava primordialmente àqueles "que compreendendo a hora presente de formação dum novo humanismo à escala universal, entendem que os negros exercitam também os seus timbres particulares para cantar na grande sinfonia humana." (LARANJEIRA, 2000, p. 20)

\section{REFERÊNCIAS BIBLIOGRÁFICAS}

ANDRADE, Francisco Tenreiro and Mário Pinto de. Poesia negra de expressão portuguesa. Para a história das literaturas africanas de expressão portuguesa. Ed. Manuel Ferreira. Linda-a-Velha: África, 1982.

ANDRADE, Mário Pinto de. A Literatura Negra e os seus problemas. Mensagem Jan.-Julho de 1951: 1-13.

Jan. de 1952: 14-17.

A Literatura Negra e os seus problemas (Parte 2). Mensagem

FERREIRA, Manuel. 50 Poetas Africanos. Lisboa: Plátano, 1986.

HUTCHINSON, George (ed.). The Cambridge Companion to the Harlem Renaissance. New York: Oxford University Press, 2007.

HUGHES, Langston. The Collected Works of Langston Hughes / Edited with an Introduction by Arnold Rampersad. Urbana: University of Illinois Press, 2001.

LARANJEIRA, Pires. Negritude africana de língua portuguesa. Texto de apoio (1947-1963). Braga: Angelus Novus, 2000.

RAMPERSAD, Arnold. The Life of Langston Hughes. Oxford; New York: Oxford University Press, 2002.

TENREIRO, Francisco José. Coração em África. Para a História Das Literaturas Africanas. Ed. Manuel Ferreira. Linda-a-Velha: África, 1982. 


\section{NOTAS}

1 No prefácio de Coração em África de Francisco José Tenreiro, Francisco J.B. Martinho afirma que "em Ilha de Nome Santo é impossível não conjugar a tónica africana de livro com a intenção social típica do neo-realismo e as presenças tutelares são as dos poetas afro-americanos da Harlem Reneissance, sobretudo Langston Hughes, de alguma poesia brasileira e, quiçá, de Nicolás Guillém". No entanto, as leituras da Literatura Africana em língua Portuguesa, especialmente a poesia, frequentemente são consistentes com as premissas desenvolvidas por Manuel Ferreira no Prefácio da antologia 50 Poetas Africanos: "estes 50 poetas e 324 poemas ajudam a compreender o que neste momento acabamos de afirmar. Algumas hesitações iniciais, as visíveis dificuldades da parte do sujeito do século XIX para se reencontrar com o seu universo africano ou cabo-verdiano; depois a fase da conquista definitiva por parte do enunciador em relação à sua identidade cultural e da sua consciência nacional; a verificação de que a terra e os homens são dominados por estranhos; o direito a si próprio; o momento poético da agressividade; a ascensão de uma esperança na fé imparável da mudança que traz consigo o ímpeto telúrico e a lucidez histórica; o modo como a língua, modelando novas linguagens, leva a novas expressões e a novos conteúdos; o modo ainda como esta poética africana vai ganhando força e transparência no exercício da expressão do real cada vez mais tenso e buliçoso; e depois os anseios, os modos quotidianos ou universais de entender o mundo; a visão nova trazida por gente nova que produz significados novos através de uma linguagem nova" (FERREIRA, 1986, p. 16)

2 Este trabalho não intenciona de forma alguma contrariar esta afirmação, muito pelo contrário, pois o que se pretende é estabelecer o diálogo e analisar os pontos de contacto e convergência entre a negritude lusófona, a negritude francófona e os movimentos de negritude nas Américas, tanto nos Estados Unidos como na América Latina, particularmente no Caribe, de forma a considerarmos o possível desenvolvimento de um movimento de Negritude Pan-Africana com objectivos e expressões comuns.

3 Este Regimento conhecido pelo cognome "Harlem Hellfighters" tinha sido organizado em 1916 e era composto por soldados Afro-Americanos e por oficiais Afro-Americanos e Anglo-Americanos e foi um dos regimentos de soldados Afro-Americanos que participaram na Primeira Guerra Mundial permanecendo no terreno durante um período recorde de mais de seis meses. Embora de forma geral o heroísmo Afro-Americano não fosse reconhecido, os homens do Regimento 369 foram galardoados colectivamente com uma Croix de Guerre e mais de uma centena dos soldados também receberam medalhas de mérito individuais concedidas tanto pelo governo Americano como pelo Francês.

4 As publicações dos textos The Big Sea de Howard Hughes, Harlem: Negro Metropolis de Claude McKay e The Negro in Art de Alain Locke são normalmente identificada como as publicações finais do Harlem Renaissance.

5 "The Harlem Renaissance in literature was never a cohesive movement. It was, rather, a product of overlapping social and intellectual circles, parallel developments, intersecting groups, and competing visions - yet all loosely bound together by a desire for racial self-assertion and self-definition in the face of white supremacy." (HUTCHINSON, 2007, p. I)

6 O primeiro congresso realizou-se em Londres em 1900, seguido por Paris (1919), Londres e Bruxelas (1921), Londres e Lisboa (1923) e Nova York (1927). Estes congressos, nos quais participavam primordialmente membros da elite negra dos Estados Unidos, defendia-se a auto-determinação dos povos africanos e o fim da descriminação a que estava sujeita a diáspora Africana.

7 Nicolás Guillén publica Motivos de Son em 1930, Sóngoro Cosongo em 1931 e West Indies, Ltd. em 1934.

8 De forma geral considera-se que este movimento cessou no momento em que se concretizaram todos os processos de independência dos países Africanos anteriormente colonizados pelos diversos poderes Europeus. No entanto, a temática do filme Rue Cases Nêgres de autoria de Josephe Zobel e direcção de E. Palcy estreado em 1983 insere-se claramente no movimento de Negritude. 
9 O texto de Pinto de Andrade é, segundo o próprio autor, "provocado por uma conferência que o Sr. Dr. Tomé das Neves pronunciou em Luanda sobre 'A Literatura Negra' e que o Brado Africano publicou no seu número de 23 de Dezembro de 1950.” (ANDRADE, 1951, p. 3)

10 Presume-se que Mário Pinto de Andrade tencionava continuar o texto pois em sua última página encontramos a referência "(conclui no próximo número)" o que acaba por não acontecer devido a interrupção de publicação do boletim.

11 A nossa referência deste texto foi retirada da sua reprodução em Negritude Africana de Língua Portuguesa. Textos de Apoio (1947-1963) de Pires de Laranjeira.

12 Publicado em Mensagem, ano XV, nº1 (Abril de 1963), Lisboa, CEI, pp3 4-10, e reproduzido em Negritude Africana de Língua Portuguesa. Textos de Apoio (1947-1963).

13 Este texto é um dos incluídos na colectânea de Pires Laranjeira Negritude Africana de Lingua Portuguesa. Textos de Apoio (1947-1963).

14 Publicado no folheto para um Recital de Poesia por Alda Lara, promovido pela Delegação de Coimbra da Casa dos Estudantes do Império, na União dos Grémios de Logistas de Coimbra, em 16-5-1963, e reeditada por Pires Laranjeira em Negritude Africana de Língua Portuguesa. Textos de Apoio (1947-1963) pp.106-108.

15 Prefácio de Coração em África. Editada por África - literatura, arte e cultura em 1982. p. 19. 